\title{
Creando Geografías: Una exploración al Territorio Integral y Memoria en la Protesta Indígena
}

\section{The Making of Geographies: Exploring Integral Territory and Memory within Indigenous Protest}

\author{
Carola Ramos ${ }^{1}$ \\ Queen's University, Canadá
}

\begin{abstract}
Resumen
El estudio de la relación entre memoria y geografía se ha enfocado principalmente en el rol del espacio construido (museos, monumentos, lugares históricos, y artefactos) en la producción de sitios de conmemoración, así como en el uso del espacio a través de representaciones o rituales para (re) crear memorias o contra-memorias por parte de grupos sociales. La reconstrucción y recuperación de un 'territorio integral' entre los pueblos amazónicos del Perú, que ellos describen como su manera ancestral de vivir, hoy es también un proyecto moderno para definir y reafirmar el control de sus territorios. A la luz de una revisión crítica de la literatura sobre memoria en geografía y análisis narrativo de entrevistas y documentos elaborados por grupos indígenas, propongo un marco conceptual para estudiar las llamadas protestas antineoliberales de los años 2008-2009 en la Amazonía peruana, usando teorías sobre la memoria colectiva y decolonialidad.
\end{abstract}

Palabras clave: memoria colectiva; decolonialidad; movimiento indígena; neoliberalismo; Perú.

\begin{abstract}
The study of the relation between memory and geography has been mainly focused on the role of the built space (e.g. museums, monuments, heritage sites, and artifacts) with the production of sites of memorialization, as well as the use of space through performance or rituals in (re)creating memories or counter-memories by social groups.

The reconstruction and recovering of an 'integral territory' among Amazonian peoples, which they describe as their ancestral way of living, is today also a modern project to define and reassert the
\end{abstract}

1 Ph.D., Queen's University, Canada. Email: carola.ramos@queensu.ca

Este artículo corresponde a la ponencia presentada en el 35th Conference of Latin American Geographers realizada en San José, Costa Rica del 20 al 22 de mayo del 2018. 
control of their territories. In the light of a critical review of the literature on memory in geography and narrative analysis of interviews and documents elaborated by indigenous groups, I propose a conceptual framework to study the so-called anti-neoliberal protests of 2008-2009 in the Peruvian Amazon drawing on collective memory and decolonial theories.

Keywords: Collective memory; decoloniality; indigenous movement; neoliberalism; Peru

\section{Introducción}

El 5 de junio de 2009, un operativo policial para desalojar a manifestantes de la carretera Fernando Belaúnde Terry, cerca de la ciudad de Bagua, terminó en tragedia. Cuando las primeras noticias se difundieron -incluyendo los disparos contra Santiago Manuin Valera, uno de los líderes Awajún más emblemáticos, quien, con las manos en alto, pedía a la policía que dejara de disparar- la violencia se trasladó a la estación de bombeo No. 6 del oleoducto de Petroperú, en Imaza - que había sido tomada por cientos de manifestantes desde hacía dos meses- y las localidades de Bagua, Bagua Grande y Jaén, donde se dieron demostraciones contra locales del Estado, así como represión policial. Conocido como el Baguazo, de acuerdo a los datos difundidos en informes oficiales, el día culminó con 33 muertos (entre 23 policías, 10 civiles, incluyendo 5 awajún-wampis) y unos 200 heridos. El bloqueo era parte de movilizaciones sociales por toda la Amazonía peruana, demandando que el Congreso derogue un conjunto de decretos legislativos que, para los amazónicos, afectaban la integridad de sus territorios, facilitando la división y comercialización de las tierras comunales.

Este artículo se basa en el trabajo de campo y revisión de literatura preliminares para una investigación que estudia las nociones de territorio y propiedad entre distintos grupos de awajún de la provincia de Condorcanqui. Propongo estudiar la protesta indígena desde los conceptos de memoria desde la Geografía y descolonialidad, a la luz de una revisión del marco legal de derechos indígenas, en contraste con la legislación objeto de protestas. En este sentido, considero que la recuperación de un "territorio integral" - la manera ancestral de vivir y un proyecto moderno de reconstrucción y control territorial - da forma a la defensa del territorio indígena y ejemplifica una geografía de resistencia a la imposición de la ley del Estado. 


\section{Área de Estudio: Una breve introducción al pueblo Awajún de la Amazonía Peruana}

Con más de 55,000 habitantes, los Awajún son el segundo pueblo indígena más Numeroso de la Amazonía peruana (INEI 2009), y se asientan mayormente en cuatro departamentos, especialmente en Amazonas (Figura 1). El antropólogo Stefano Varese advertía que el milenario pasado inca de Perú ha situado al país como un "país andino", dejando de lado o haciendo invisible la realidad amazónica (Varese, 1972, citado por Greene, 2006). Las historias de resistencia de los Awajún se remontan a tiempos anteriores a la llegada de los españoles, en la época de los incas, y luego en contra de las misiones españolas que siguieron (Ministerio de Cultura: Base de Datos de Pueblos Indígenas; ODECOFROC 2010; Brown 1984; Hill 2008; Regan 2010). 
Carola Ramos. The Making of Geographies: Exploring Integral Territory and Memory within Indigenous Protest

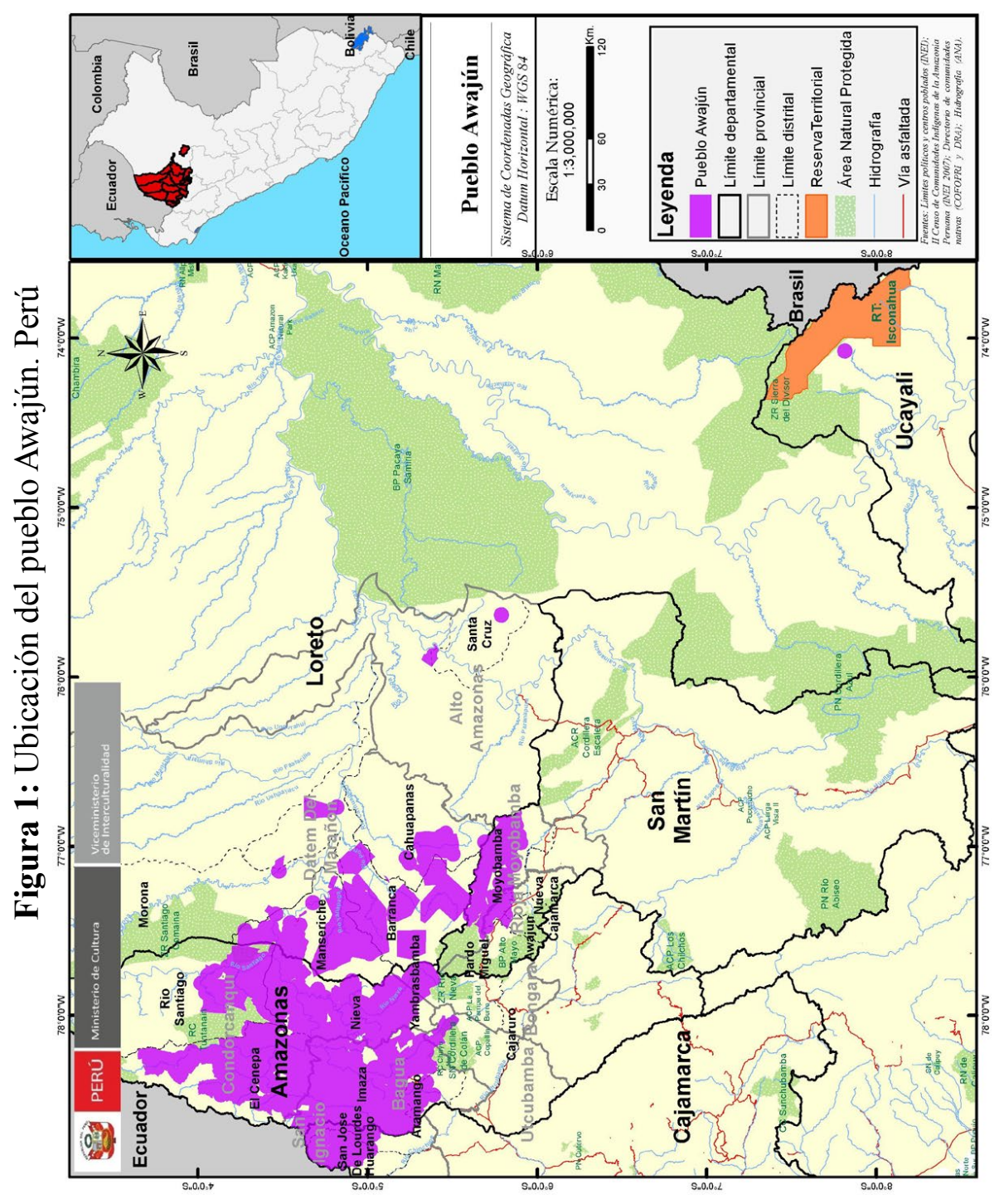

ป̊

Revista Geográfica de América Central № 61E (3) Especial CLAG Este artículo está bajo una licencia ISSN 1011-484X • Julio-diciembre 2018・pp. 137-153 Doi: http://dx.doi.org/10.15359/rgac.Esp-3.8 
Sin embargo, es durante la época republicana que se dio una interacción más constante entre los pueblos de la Amazonía y la cultura criolla y mestiza dominantes, aunque no mayoritaria ${ }^{2}$. Diversos gobiernos han visto en la Amazonía una tierra vacía y desperdiciada, de la cual se debe extraer riquezas (caucho, madera, petróleo, oro, etc.) o que debe ser colonizada por campesinos migrantes de otras zonas del país (Espinosa, 2009, 152).

Las relaciones entre los indígenas amazónicos, como los awajún, y el resto de la sociedad peruana, se dieron de manera más continua desde la segunda mitad del siglo XX. Por un lado, la escolarización progresiva (de parte de misiones evangélicas y católicas), que trajo nuevos conocimientos y valores (Greene 2006, 340), así como el desarrollo de carreteras y la migración de colonos de otras partes del país promovida por el Estado peruano, e invasiones, que causaron la pérdida de territorios tradicionales y recursos naturales, afectando su subsistencia (Benavides 2010, 267), e inclusive ataques directos de agentes del Estado, como en el caso de los indígenas matsés en 1964 (ver: Espinosa, 2009, 144-145), demostrando el desprecio por las vidas indígenas.

En este contexto, los amazónicos se dieron cuenta de la importancia de contar con nuevos instrumentos para lograr relaciones más igualitarias, tales como el idioma español, conocimientos legales, comerciales y administrativos (Greene 2006, 340; Garra y Riol 2014, 62-63; Espinoza 2009, 144-145) y la formación de alianzas beneficiosas para sus fines (Silvia Romio 2014), a nivel nacional e internacional (Benavides 2010, 267; Smith 1996, citado en: Greene 2006, 342).

\section{Marco Legal de Derechos Indígenas}

En la década del 70, el Gobierno Revolucionario de las Fuerzas Armadas del general Juan Velasco Alvarado implementó la Reforma Agraria en Perú, promoviendo un sistema de titulación de tierras rurales que reconocía la existencia y capacidad legal de las comunidades nativas en la selva y de comunidades campesinas en la sierra. Aunque para grupos indígenas como CORPI $(2002,46)$, este sistema seguía el modelo de comunidad agraria andina, basado en la posesión de un grupo de familias, sin considerar las diferencias con los pueblos amazónicos; no obstante, destacaban tres principios que hasta ahora sirven de base para las demandas

2 Después de la independencia, la población indígena ascendía a 2/3 del total (Orihuela, 2012, 689). 
de derechos de los pueblos indígenas: inalienabilidad, inembargabilidad, e imprescriptibilidad (Decreto Ley 20653, Ley de Comunidades Nativas y de Promoción Agropecuaria de Regiones de Selva y Ceja de Selva, 1974). Básicamente, estos principios garantizarían la propiedad colectiva, al no poder ser transferida.

Sin embargo, poco tiempo después, el Decreto Ley No. 21147, Ley Forestal y de Fauna Silvestre (1975), estableció que los recursos forestales (incluyendo aquellos sin capacidad agrícola) son de dominio público. Asimismo, el Decreto Ley No. 22175, Ley de Comunidades Nativas y de Desarrollo Agrario de la Selva y de Ceja de Selva, estableció que las tierras de comunidades nativas con aptitud forestal podían ser otorgadas en uso a comunidades nativas (no en propiedad), lo cual afectaba la integridad del territorio comunal (García Hierro, 2017 [2014]; Manacés y Gómez, 2010, 27-28).

La década de los 80 s marcó un periodo de consolidación de derechos y alianzas internacionales. A nivel nacional, se fundó AIDESEP - Asociación Interétnica de Desarrollo de la Selva Peruana - y a nivel transnacional, COICA - la Coordinadora de las Organizaciones Indígenas de la Cuenca Amazónica, la cual empezó a promover derechos territoriales a escala global, con grupos conservacionistas, gobiernos y entidades internacionales como el Banco Mundial, el Banco Interamericano de Desarrollo y el Grupo de Trabajo sobre Pueblos Indígenas de la ONU (Smith, 2003). En 1989, el Convenio 169 de la Organización Internacional del Trabajo, sobre Pueblos Indígenas y Tribales, reconoce derechos territoriales a los pueblos indígenas, y entra en vigencia en Perú desde febrero de 1995.

En los 90s, con la neoliberalización de la economía durante el régimen de Fujimori ${ }^{3}$, el Decreto Legislativo No. 26505 - Ley de la inversión privada en el desarrollo de las actividades económicas en las tierras del territorio nacional y de las comunidades campesinas y nativas - aprobado bajo el marco de la Constitución de $1993^{4}$, estableció la posibilidad

3 A principios de los 90s, el gobierno de Alberto Fujimori (1990-2000) introdujo reformas económicas orientadas a la promoción de inversión extranjera y la creación de incentivos, particularmente en minería e hidrocarburos. Con un nuevo marco legal favorable, para el año 2009 , un $72 \%$ de la Amazonía peruana se encontraba destinada a actividades de hidrocarburos, de las cuales un $48.6 \%$ había sido otorgada a concesiones de petróleo y de gas (un salto desde $7.1 \%$ en 2003). Estas áreas se superponían en un $17.1 \%$ con el sistema de áreas protegidas de la Amazonía peruana y más de la mitad de las tierras indígenas tituladas (Finer and Orta-Martínez, 2010).

4 La Constitución de 1993 solo mantuvo la garantía de imprescriptibilidad, excepto en caso de abandono, lo cual se consideraba una amenaza para el territorio amazónico porque, por su naturaleza forestal - a diferencia de las tierras en la Costa o los Andes - tiene diferentes ciclos de producción, por lo que, por temporadas, 
de transferir tierras indígenas con el acuerdo de por lo menos $2 / 3$ de los miembros de la comunidad, lo cual ya había sido reconocido en la Constitución de 1979.

Aunque la reducción de la protección de derechos de los pueblos indígenas empezó desde mediados de los 70s, para Gil Inoach (entrevista, 23 de junio de 2017), abogado awajún, antiguo presidente de AIDESEP y consejero legal del Gobierno Territorial Autónomo de la Nación Wampis, y para Ermeto Tuesta (entrevista, 26 de julio de 2017), experto en GIS y consultor de CORPI, es la Constitución de 1993 y la Ley No. 26505, lo que habría provocado la respuesta indígena para evitar la pérdida de la integridad de sus territorios. Según Inoach (2015), esta normatividad preparaba el terreno para llevar a los pueblos indígenas a la "modernidad", imponiéndoles una economía de mercado. Al promover la división y transferencia de tierras colectivas, la Ley No. 26505, además, permitía reconfigurar las comunidades nativas y campesinas hacia un modelo empresarial, de manera similar al paquete de normas del año 2008 (Manacés y Gómez, 2010, 29).

Entonces, cuando el 2008 el presidente García emitió un paquete de decretos legislativos para implementar el Tratado de Libre Comercio con los Estados Unidos, incluyendo algunos que excedían este marco, orientados a facilitar la división y comercialización de tierras indígenas, los indígenas amazónicos, a través de su organización nacional AIDESEP, se opusieron a ellos. Conociendo los antecedentes del movimiento indígena, descritos en las líneas anteriores, es posible entender este conflicto como un conflicto entre dos órdenes o "maneras de hacer" (usando el término de Raúl Zibechi, en Hardt y Reyes, 2012): por un lado, un orden que promueve las inversiones y la propiedad privada y busca llevar a los amazónicos a la modernidad (Stetson 2012), y por otro lado, un orden que busca mantener la propiedad colectiva, a través de su proyecto para recuperar y controlar los territorios integrales.

\section{EI Territorio Integral como un Proceso y Orden}

Ante las presiones infligidas por el Estado, en 1995, en la localidad de San Lorenzo, en la actual provincia de Datem del Marañón, departamento de Loreto, un grupo de indígenas pertenecientes a nueve pueblos, ${ }^{5}$ 
incluyendo al Awajún, fundaron CORPI, la Coordinadora Regional de los Pueblos Indígenas, la cual comenzaría a concebir los territorios integrales como un proceso a seguir para defender los territorios (Inoach 2015, 69).

Mientras las regulaciones vigentes reconocían la titulación de comunidades nativas y no de pueblos indígenas, CORPI promovía que los nueve pueblos identifiquen sus territorios integrales, para solicitar la titulación de las áreas que faltaba titular y de esa manera completarían las “piezas" faltantes del rompecabezas (CORPI et al. 2002, 89) (Figura 2). La reconstrucción del territorio integral de cada pueblo implicaba consultar a los miembros de las comunidades sobre: la "[m]emoria histórica, mitos y visiones definitorias del territorio y toponimia tradicional", así como los recursos del territorio y su estado actual (CORPI 2002, 94). Sin embargo, CORPI et al. $(2002,72)$ reconocen que en la historia de los pueblos jíbaros (grupo etnolingüístico al que los awajún pertenecen), algunos grupos pueden haberse desplazado por distintas razones o incluso cambiado de nombre. Por ello, la definición territorial estaría enmarcada a la coyuntura presente. Además, como Ermeto Tuesta (entrevista, 26 de julio de 2017) explica, algunos mapas que él elabora son objeto de modificaciones, debido al cambio de dirigentes de las federaciones indígenas, que muchas veces conlleva al cambio de criterios también.

Para Shapiom Noningo, secretario técnico de la Nación Wampis (el primer pueblo de los nueve en constituirse como gobierno autónomo en Perú), el territorio integral "no es una idea, sino es... nuestra propia forma de vida, que existió desde miles de años", en conexión con cada elemento del bosque, que no se puede separar (entrevista, 20 de junio de 2017). En términos técnicos, Ermeto Tuesta (2017), quien ha liderado los procesos de elaboración de los mapas integrales, desde su experticia en GIS, lo explica de este modo:

su territorio [del indígena] es donde caza, pesca, recolecta, de forma tradicional. Entonces, (...) cuando le dan su título de acuerdo al número de personas y a un número de familias, tantas hectáreas, le dan... áreas pequeñas... pero... el indígena (...) se va más allá... ¿no?, entonces el territorio integral... como que le da... su territorio real; (...) eso uno se da cuenta cuando hace el mapeo de usos-recursos con las comunidades nativas. 
Esta es la visión de líderes awajún-wampis que han trabajado en el desarrollo de territorios integrales desde los 90s. En términos actuales, para Elmer Ujukam, un miembro Awajún del Consejo Permanente del Pueblo Awajún, el territorio integral está en proceso de materializarse a través de procesos participativos para aprobar la constitución del gobierno autónomo del Pueblo Awajún. Además, el concepto de integralidad se traslada también a la chacra o huerta awajún. Así como en el territorio integral, la chacra integral también apela a la memoria del pasado:

Antes, nuestros abuelos han manejado una chacra integral... Hoy en día, la gente ha venido perdiendo. Se han convertido en monocultivos de chacras hoy día...

... la idea es... a través de esos jóvenes [líderes] recuperar la chacra integral que fue.

Recuperar la chacra integral que fue porque (...) nuestras mamacitas se iban a la chacra, no solamente traían pura yuca... nos traía papaya, nos traía (...) ... cocona. Nos traía... caña dulce. Nos traía (...) ... piña... y más frutas para cocinar. Entonces, a la hora del almuerzo, (...) ponía la sachapapa, ponía (...) papa china... todo eso... cocinaba. Entonces, nuestras madres, [por] más que haya pescado (...), [por] más que haya carne, primero nos hacía comer esto... Por eso, nosotros (...) hemos crecido... fuertes y sanos.

Aquí la memoria parece dar forma a estrategias indígenas para preservar su cultura. De modo similar, con relación al movimiento katarista frente al fracaso del proyecto homogeneizador del Movimiento Nacionalista Revolucionario, Silvia Rivera $(2010,214)$ advierte que "el katarismo extrae sus reivindicaciones del pasado indio prehispánico y colonial (...). La percepción de la continuidad colonial revela el predominio de la memoria larga sobre la memoria corta y es fuente de identidad política autónoma." Aquí colonialidad y descolonialidad parecen coexistir, como en los 
awajún, cuando tratan de reafirmar sus territorios integrales usando mapas, basados en derechos indígenas contenidos principalmente en el Convenio 169, que hoy es parte del derecho interno.

Figura 2: CORPI: Territorio integral por pueblo indígena

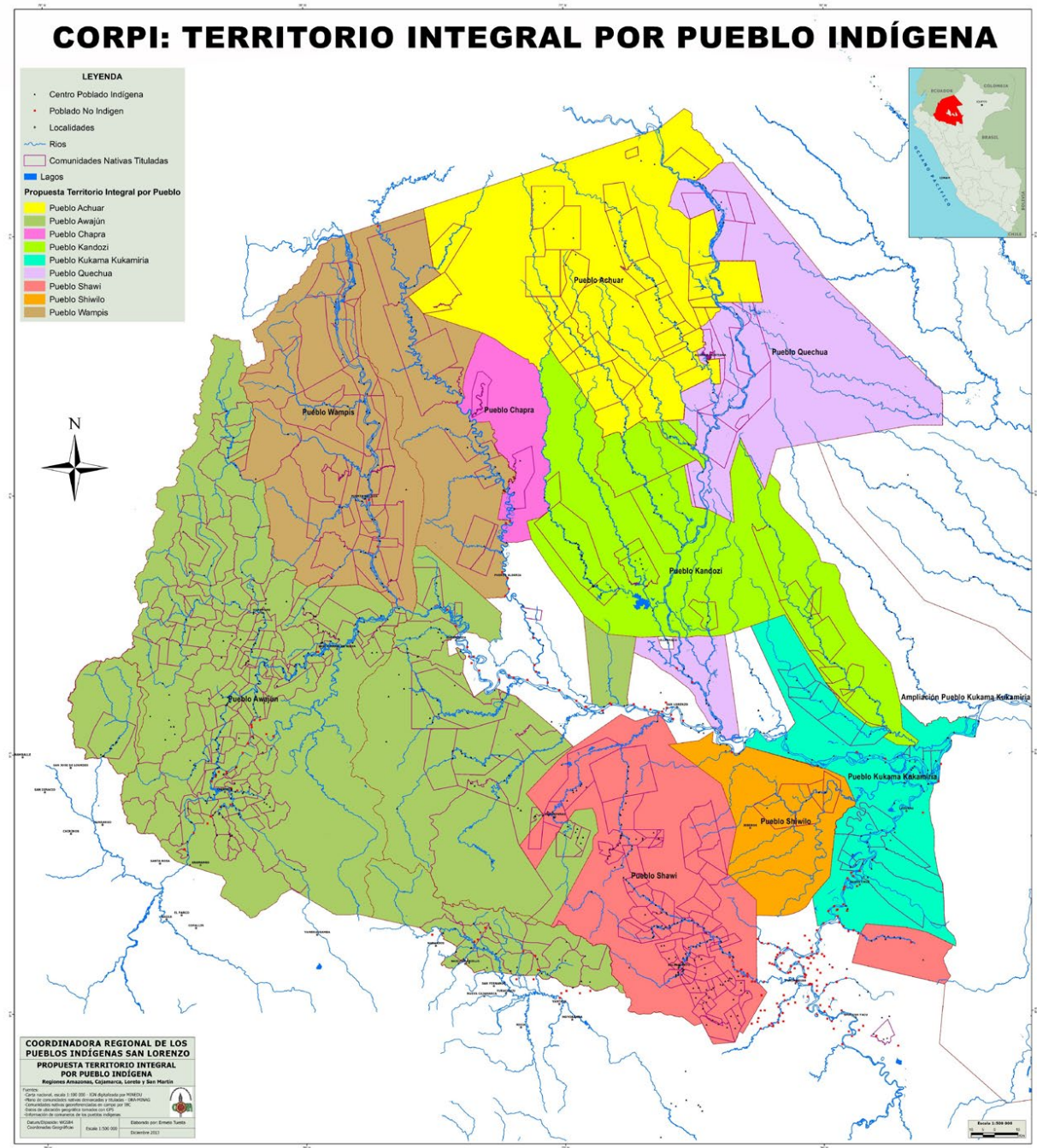

Elaborado por: Ermeto Tuesta, 2013. 


\section{El Concepto de Memoria en Geografía}

Trabajos sobre memoria en geografía humana se han ocupado principalmente en el rol del ambiente físico (como museos, monumentos, lugares históricos) en crear un sentido de identidad a través de la memoria; o prácticas para crear memoria a través de representaciones o rituales para recordar (Gregory 2009, 453-454; Hoelscher y Alderman 2004, 350).

Los geógrafos han contribuido a los estudios sobre memoria con dos ideas centrales (Till y Kuusisto-Arponen, 2015, 293). Aquellos que trabajan en base a la memoria buscan "ganar autoridad para representar su visión del pasado en espacios públicos", donde espacio público no solo es el ambiente construido, sino también los medios o tecnologías gubernamentales como la ley. Además, se resalta la naturaleza translocal y transgeneracional de la memoria (294). La política del uso de la memoria está ligada a otro tiempo y lugar, no limitado a un espacio físico determinado ${ }^{6}$.

La memoria también ha sido estudiada en relación con hechos violentos y traumáticos, como guerras, conflictos, desplazamientos, masacres o desastres naturales. En América Latina, la literatura sobre memoria está ligada a periodos de violaciones de derechos humanos durante guerras civiles o regímenes autoritarios, como ha ocurrido en países de América Central y del Sur. Sin embargo, en base al trabajo de campo y revisión de literatura preliminares, la evocación del pasado en los awajún parece responder a fines de estrategia de preservación cultural o defensa territorial, y también como una experiencia de aprendizaje ${ }^{7}$, lo cual relaciono con la teoría de la investigación basada en deseo (“desire-based research") de Eve Tuck (2009), según la cual no se trata de negar la tragedia, el trauma o el dolor sino de situar el conocimiento derivado de este tipo de experiencias como algo sabio (Tuck y Yang 2014, 231).

6 Sigo la clasificación del espacio, en absoluto, relativo y relacional (Harvey, 2005) y la definición de Massey de espacio relacional, como el producto de interrelaciones, donde trayectorias heterogéneas coexisten y está constantemente en construcción (2005).

7 Hablando sobre su experiencia como presidente del Consejo Aguaruna-Huambisa en Condorcanqui a principios de los 90s, Santiago Manuin (entrevista, 17 de junio de 2017) explicó que la experiencia del pueblo asháninka de la selva central, al ser divididos por la invasión de grupos terroristas (MRTA y Sendero Luminoso) y la intrusión del ejército en su territorio durante los $80 \mathrm{~s}$, motivó que los awajún comenzaran a controlar su territorio, implantando la necesidad de contar con un carnet de comunero. 


\section{Metodología y Limitaciones}

Este artículo es el resultado de un trabajo en proceso para investigar las nociones de territorio y propiedad entre distintos grupos de awajún de la provincia de Condorcanqui. Me baso en cinco entrevistas semi-estructuradas con líderes awajún y un wampis, y la revisión de documentos elaborados por grupos indígenas (CORPI, ODECOFROC, y Jesús Manacés, miembro awajún que elaboró el informe en minoría sobre los sucesos de Bagua, junto con Carmen Gómez), así como algunos aliados como García Hierro (2014).

El concepto de memoria no ha sido utilizado como método para recolectar datos durante las entrevistas (Kneightley, 2010), sino que ha sido un tema que ha emergido en un análisis preliminar y que podría servir para interpretar discursos y escenas objeto de observación. Sin embargo, por ahora mis interpretaciones se limitan a un grupo limitado de personas, y se enmarcan en mis experiencias como peruana, abogada e inmigrante en Canadá.

\section{Conocimiento Geográfico Indígena: Conectando Memoria y Te- rritorio Integral}

Siguiendo la definición de memoria de Halbwachs (1992), la política del territorio integral surge bajo el contexto o presión por los cambios legales que facilitarían la invasión de territorios y proyectos extractivistas. Gil Inoach (entrevista, 23 de junio de 2017), en su calidad de asesor legal del Gobierno Territorial Autónomo de la Nación Wampis, describe:

... hay una reacción... si nosotros no visibilizamos cómo controlamos nuestro territorio... pronto van a venir a invadirnos (...). Pronto van a ser subastados. ¡No! Es momento de visibilizarnos

... si nosotros estamos esperando, dependemos de dispositivos administrativos... para consolidar nuestro territorio... eso nunca va a ser... Nosotros tenemos que visibilizar tal como conservamos el territorio... hasta que el Estado llegue en (...) algún tiempo... comprender.

De acuerdo a Karen Till (2012), aquellos que trabajan en la memoria, a menudo demandan visibilidad pública, la cual ella relaciona con el derecho a la ciudad en un contexto urbano. En este sentido, visibilizar los territorios integrales aparece como una estrategia para proteger sus tierras, de lo contrario, pronto van a venir a invadirnos. Para la Nación Wampis 
además, representa un desafío para el Estado: hasta que el Estado llegue (...) en algún tiempo... comprender.

La memoria es usada estratégicamente y se materializa en un mapa y una acción o proceso. El mapa parece ser más que una representación del espacio (siguiendo la clasificación espacial de Harvey, 2005). Por ejemplo, los awajún elaboraron un mapeo histórico-cultural para demostrar cómo concesiones mineras en la zona de la Cordillera del Cóndor, en la frontera con Ecuador, se superponen con áreas de uso de recursos naturales y sitios sagrados (que no han sido titulados), con el fin de demandar la nulidad de dichas concesiones a autoridades del sector minero.

El mapeo de territorios integrales hace uso de memorias de geografías, pero no refuta otra versión del pasado, a modo de una contra-memoria (Courtheyn, 2015), sino más bien resulta ser una herramienta para oponerse a las leyes dictadas por el gobierno, que pretenden cambiar el presente y futuro del territorio indígena. De este modo, la memoria sirve para preservarse como cultura, como cuando Santiago Manuin (entrevista, 17 de junio de 2017) explica que "hay que proteger el bosque porque dependemos del bosque", de lo contrario, "no podemos autodeterminarnos como pueblo".

Estudios sobre el Baguazo han resaltado el legado del colonialismo en las relaciones entre el Estado y los pueblos indígenas (Stetson 2012, Rénique 2009, Merino 2015). Colonialismo que se manifestó desde los discursos del entonces presidente García (2008), comparando a los indígenas con un "perro del hortelano" que irracionalmente cuida la huerta, manteniéndola sin cultivar, porque carece de tecnología y recursos, y a la vez no deja que otros la aprovechen, así como también en la medida de fuerza ordenada para desalojar violentamente la carretera, convirtiendo dicho operativo en una batalla entre peruanos.

Aproximarnos al movimiento amazónico desde la geografía implica estar dispuesto a desestabilizar la disciplina para reconocer el conocimiento desde los movimientos sociales. Descolonizar la geografía significaría así no solamente reconocer los logros y las estrategias de grupos indígenas, sino más que todo tomar en serio su producción para analizarla críticamente como fuente de conocimiento y contrastarla con la realidad (Noxolo 2017). Por ello, mis próximos pasos me llevarán a conversar con lideres de base comunal en el pueblo de Santa María de Nieva, más allá de los clásicos líderes hombres, y observar sus prácticas para usar y organizar el territorio a nivel individual, comunal o colectivo. 


\section{Referencias}

Benavides, M. (2010). Industrias extractivas, protesta indígena y consulta en la Amazonía peruana. Anthropologica, 28: 263-287.

Brown, M. (1984). Una paz incierta: historia y cultural de las comunidades aguarunas frente al impacto de la carretera marginal. Lima: CAAAP.

CORPI, Racimos de Ungurahui, y Grupo Internacional de Trabajo sobre Asuntos Indígenas (IWGIA). (2002). Una historia para el futuro: Territorios y Pueblos Indígenas en Alto Amazonas. Santa Cruz de la Sierra: Sirena Color.

Courtheyn, C. (2015). “"Memory is the strength of our resistance': an 'other politics' through embodied and material commemoration in the San José Peace Community, Colombia.” Social \& Cultural Geography, 17(7): 933-958.

Espinosa, O. (2009). “¿Salvajes opuestos al progreso? Aproximaciones históricas y antropológicas a las movilizaciones indígenas en la Amazonía peruana." Anthropologica, 27: 123-168.

Finer, M. y M. Orta-Martínez. (2010). “A second hydrocarbon boom threatens the Peruvian Amazon: trends, projections, and policy implications." Environmental Research Letters, 5: 1-10.

Garcia, A. (2007, 28 de octubre). "El síndrome del perro del hortelano". El Comercio. Recuperado: https://elcomercio.pe/edicionimpresa/ html/2007-10-28/el_sindrome_del_perro_del_hort.html

García Hierro, P. (2017). “Argumentos básicos acerca de la irracionalidad e inconstitucionalidad del contrato de cesión en uso de suelos forestales en territorios indígenas." Recuperado: http://nuestrosderechos.pe/ argumentos-basicos-acerca-de-la-irracionalidad-e-inconstitucionalidad-del-contrato-de-cesion-en-uso-de-suelos-forestales-en-territorios-indigenas/. [Artículo original en: www.justiciaviva.org.pe, $11 \mathrm{de}$ setiembre de 2014].

Garra, S. y R. Riol. (2014). "Por el curso de las quebradas hacia el 'territorio integral indígena': Autonomía, frontera y alianza entre los awajún y wampis." Anthropologica, 32: 41-70.

Greene, S. (2006). "Getting over the Andes: The Geo-Eco-Politics of Indigenous Movements in Peru's Twenty-First Century Inca Empire." 
Journal of Latin American Studies, 38: 327-354. DOI: http://dx.doi. org/10.1017/S0022216X06000733.

Johnson, N. y G. Pratt. (2009). "Memory.” En R. Johnston, G. Pratt, M. Watts, y S. Whatmore (Eds.) The Dictionary of Human Geography (pp. 453-455). Recuperado de: https://ebookcentral-proquest-com. proxy.queensu.ca.

Halbwachs, M. (1992). On collective memory. Chicago: University of Chicago Press.

Hardt, M. and Reyes, A., (2012). "New Ways of Doing”: The Construction of Another World in Latin America: An Interview with Raúl Zibechi. South Atlantic Quarterly, 111(1), 165-191.

Harvey, D. (2005). "Space as a Key Word.” En Spaces of Neoliberalization: Towards a Theory of Uneven Geographical Development [2004 Hettner Lectures, Department of Geography, Heidelberg] (pp. 91115). Stuttgart: Franz Steiner Verlag.

Hill, J. D. (2008). "Indigenous Peoples and the Rise of Independent Nation-States in Lowland South America." En F. Salomon y S. B. Schwartz The Cambridge Historyof the Native Peoples of the Americas (pp. 704-764). http://dx.doi.org/10.1017/CHOL9780521630764.012 Hoelscher, S. y D.A. Alderman. (2004). "Memory and place: Geographies of a critical relationship." Social \& Cultural Geography (5) 3: 347-355.

Inoach, G. (2015). "Caminando con Perico." En A. Chirif (Ed.) Querido Perico: Pedro García Hierro, defensor de los derechos de los pueblos indigenas (pp. 63-73). Lima: International Work Group for Indigenous Affairs (IWGIA).

Instituto Nacional de Estadística e Informática - INEI. (2009). Resultados Definitivos de las Comunidades Indígenas. Censos Nacionales 2007: XI de Población y VI de Vivienda. Resumen Ejecutivo. Lima: INEI. Kneightley, E. (2010). "Remembering research: memory and methodology in the social sciences." International Journal of Social Research Methodology, 13(1): 55-70.

Manacés, J. y C. Gómez. (2010). "Informe en Minoría de la Comisión Especial para Investigar y Analizar los Sucesos de Bagua". Recuperado: http://www.caaap.org.pe/documentos/INFORME_MINORIA_ CAPITULOS.pdf 
Massey, D. (2005). For Space. London;Thousand Oaks, Ca; New Delhi: SAGE.

Merino, R. (2015). "The politics of indigenous self-determination: Extractive industries, states policies and territorial rights in the Peruvian Amazon." PhD diss., University of Bath, United Kingdom.

Ministerio de Cultura. Pueblo Awajún. Base de datos de Pueblos Indígenas y Originarios. Recuperado: http://bdpi.cultura.gob.pe/pueblo/awajun

Noxolo, P. (2017). "Introduction: Decolonising geographical knowledge in a colonised and re-colonising postcolonial world." Area, 49.3: 317-319.

Organization for the Development of the Border Communities of El Cenepa (ODECOFROC). (2010). A Chronicle of Deception: Attemps to transfer the Awajún Border Territory in the Cordillera del Cóndor to the Mining Industry (Report 5). International Work Group for Indigenous Affairs (IWGIA). Recuperado: http://www.iwgia. org/publications/search-pubs?publication_id=10

Orihuela, J.C. (2012). "The Making of Conflict-Prone Development: Trade and Horizontal Inequalities in Peru." European Journal of Development Research, 24 (5): 688-705.

Regan Mainville, J. (2010). "Los awajún y wampís contra el Estado: una reflexión sobre antropología política.” Investigaciones Sociales, 14: 19-35.

Rénique, G. (2009). "Law of the Jungle in Peru: Indigenous Amazonian Uprising against Neoliberalism." Socialism and Democracy, 23(3), 117-135. DOI: 10.1080/08854300903290835.

Rivera Cusicanqui, S. (2010). Oprimidos, pero no vencidos: Luchas del Campesinado Aymara y Quechwa, 1900-1980 (4ª. Ed.). La Paz: La Mirada Salvaje.

Romio, S. (2014). "Entre discurso político y fuerza espiritual. Fundación de las organizaciones indígenas awajún y wampis (1977-1979).” Anthropologica, 32: 139-158.

Stetson, G. (2012). "Oil Politics and Indigenous Resistance in the Peruvian Amazon: The Rhetoric of Modernity Against the Reality of Coloniality." The Journal of Environment \& Development, 21(1): 76-97.

Smith, R.C. (2003). "Los indígenas amazónicos suben al escenario internacional: Reflexiones sobre el accidentado camino recorrido". En F. 
Morin y R. Santana (Eds.). Lo transnacional: Instrumento y desafio para los pueblos indígenas (203-241). Quito: Ediciones Abya Yala.

Stetson, G. (2012). "Oil Politics and Indigenous Resistance in the Peruvian Amazon: The Rhetoric of Modernity Against the Reality of Coloniality." The Journal of Environment \& Development, 21(1): 76-97.

Surrallés, A. y P. García Hierro. (2004). "Introduction." En Tierra Adentro: Territorio Indígena y Percepción del Entorno, \#39, (pp. 9-22). Recuperado: http://www.iwgia.org/publicaciones/ buscar-publicaciones?publication_id=331

Till, K. E. (2012). "Wounded cities: Memory-work and a place-based ethics of care." Political Geography (31) 1: 3-14.

Till, K. E. and Kuusisto-Arponen, A.K. (2015). "Towards responsible geographies of memory: Complexities of place and the ethics of remembering." Erdkunde (69) 4: 291-306.

Tuck, E. (2009). "Suspending Damage: A Letter to Communities." Harvard Educational Review (79) 3: 409-427.

Tuck, E. and Yang, K. W. (2014). "R-Words: Refusing Research.” En D. Paris y M. T. Winn (Eds.) Humanizing research: Decolonizing qualitative inquiry with youth and communities (pp. 223-247). Los Angeles; London; New Delhi; Singapore; Washington DC: SAGE. 
